\title{
Construction use of abandoned soils
}

\author{
Hsin-Yu Shan ${ }^{a, *}$, Jay N. Meegoda ${ }^{b}$ \\ ${ }^{a}$ Department of Civil Engineering, National Chiao Tung University, Taiwan \\ ${ }^{\mathrm{b}}$ Department of Civil and Environmental Engineering, New Jersey Institute of Technology, NJ, USA
}

\begin{abstract}
Taiwan is a county under rapid development. Excavation in thousands of construction sites generated a huge amount of soils. In many cases, the soils are disposed randomly such that they are termed abandoned soils. A comprehensive study was conducted to investigate for reuse options of these soils: sub-grade construction, cement block production, structural concrete production, and asphalt concrete production. Five soils, representing predominant soil types in Taiwan were selected in this study. The compaction test results demonstrated that all five soils were suitable for subgrade construction. The compression tests for cement mortar showed that all soils produced mixes with strengths higher then $3.45 \mathrm{MPa}$ and may be used to make cement blocks. The compressive strength test results of soil concrete samples showed that all soils except for the mix having $100 \%$ of soil No. 5 produced strengths higher than $17.25 \mathrm{MPa}$. The wet/dry durability test showed that the pozzolanic action of the soil concrete samples continued beyond 28 days and there seemed to be no detrimental effects. A comprehensive mix design was performed for each soil type and also developed a control mixture to test the use of abandoned soils in hot mix asphalt concrete. The study demonstrated that with proper design even clayey soils can be used to produce construction materials. (C) 1998 Elsevier Science B.V.
\end{abstract}

Keywords: Abandoned soils; Compressive strength; Construction

\section{Introduction}

The rapid development of Taiwan and especially in the major cities has opened numerous construction sites. The excavations in the cities generate tens of thousands of tons of construction soil per year needing proper disposal. However, for reasons such as lack of appropriate disposal sites and construction contractors' unwillingness to spend extra fees for disposing the soil, much of the excavated soils are not disposed properly. Instead of trucking the soil to the designated disposal sites, truck drivers dispose the construction soils in empty sites, valleys, streams, or simply alongside the roadways.

\footnotetext{
* Corresponding author.
} 
These abandoned soils are causing major civil infrastructure and environmental problems in Taiwan.

On the other hand, the construction industry in Taiwan had been relying on dredging from the rivers to obtain the fine aggregates for construction. However, the administration has tightened the regulations on dredging from major rivers in Taiwan. There is an immediate need for finding alternate sources of fine aggregates. The reuse of construction soils may be a viable solution for the construction industry.

This study aimed at solving the problem by returning the abandoned soil to the economic mainstream as construction products. The soil can be transported to the nearest construction material production site such as an asphalt plant which serves a soil recycling center. Construction material production sites need construction material such as sand, crushed stone, and gravel that is usually trucked from faraway places. By using the soil as replacement for construction material, truck traffic going out of the city to disposal sites and coming into the city with raw material will be reduced. More importantly, this will help in stopping the random disposal of construction soils in the countryside.

The four possible reuse options are briefly discussed in the following sections.

(1) Use as pavement sub-grade material. The construction soil could be used as borrow pit soil for the construction of sub-base for roads and parking lots. This may be the most probable reuse option for abandoned soil. Construction soil can be treated as being similar to the borrow pit soils where the soils are screened for large particles and are placed in layers. The soil should be thoroughly blended to avoid the variation in soil type from one truck load to another.

(2) Use in the production of construction bricks. Construction blocks made of sand mixed with cement are used extensively in Taiwan for the construction of high-rise buildings. Most of the construction blocks are used for non-load bearing walls between concrete columns and beams. The strength of soil cement depends on the soil type and water cement ratio, which is a function of the soil type. Cement blocks made with clay soils are weaker and need long setting times whereas cement blocks made with sand are stronger and need short setting times and low water cement ratio. The soil cement blocks should be used as inner material of buildings, where they should be covered with ceramic tiles or with plaster which act as a barrier in preventing the release of any contaminants (if any) in the original soil.

(3) Use in cement industry. Construction soil as sand replacement material for the production of low strength structural concrete. The structural concrete used for side walks and ground floor slabs can accommodate low strength concrete made with soils. To date, most of the research performed on soil in concrete production was limited to using contaminated recycled concrete as aggregate in producing new or fresh concrete [1]. Soil cement has been used in many developing countries as non-load bearing construction. Soil can be used as replacement material for sand. The clay particles will reduce the strength and increase the setting time. However, these adverse effects of adding construction soil can be minimized by increasing the cement content or using the polymer modified cement in the concrete.

(4) Use in hot mix asphalt concrete. Construction soil as aggregate replacement material for the production of hot mix and cold mix asphalt concrete. The materials in 
hot mix asphalt (HMA) consists of (a) course aggregates or gravel with size as large as $1.5^{\prime \prime}$ to US sieve No. 4, (b) fine aggregate or sand with sizes passing US sieve No. 4 and retained in US sieve No. 200, (c) mineral filler such as crush stone dust or lime passing US sieve No. 200, and (d) asphalt cement. A typical HMA composition consists of 50\% coarse aggregates, $40 \%$ fine aggregate, $5 \%$ mineral filler, and 5\% asphalt cement.

Typically $5-10 \%$ wastes such as recycled asphalt pavements, tire rubber, glass, municipal solid waste (MSW) ash, roofing shingles, polythene waste, ore slug, and petroleum contaminated soils are added to HMA without sacrificing its strength and performance $([2,3]$, and [4,5]). Usually separate mix designs are not performed for inclusion of up to $5 \%$ of such waste material. Either the amount of material in the original mix is proportionately reduced, or those waste products replace the mineral filler.

Strength or stability, durability, and workability are the primary design factors in an asphalt concrete mix design. The secondary factors are flexibility, permeability, fatigue resistance, skid resistance, and stripping action ([6]).

\section{Soils tested}

Five soils from different parts of Taiwan were tested in this project. Since the soil samples are taken from the field, the following may be assumed: the soil samples are weathered and mixed with waste materials and construction debris. The results of particle size analysis and the classifications of five soils are summarized in Table 1.

\subsection{Soil type 1-a light brown silty sand from Hsinchu}

Soil 1 was obtained from a slope levelled for building construction in Hsinchu. The average water content of the soil was $6.3 \%$. The soil had no plasticity or liquid limit. More than $50 \%$ of the soil was retained on No. 100 sieve. However, wet sieve analysis produced a completely different result with $64.6 \%$ passing No. 100, 39.8\% passing No. 200, 29.9\% passing No. 325, and $19.4 \%$ passing No. 400 . Results indicated that the soil is a poorly graded fine sand.

\subsection{Soil type 2-a dark gray sandy silt from Taipei}

A second soil for test was obtained from the Chung-ho Line subway construction site in Taipei, at a depth of $5 \mathrm{~m}$. Its initial water content was $21.2 \%$. The soil had no

Table 1

Summary of soil classification data

\begin{tabular}{lccll}
\hline Soil type & $c_{\mathrm{u}}$ & $c_{\mathrm{c}}$ & $D_{10}(\mathrm{~mm})$ & Soil classification \\
\hline Soil 1 & 2.4 & 1.3 & 0.08 & Poorly graded fine sand \\
Soil 2 & 2.5 & 1.1 & 0.07 & Poorly graded sand \\
Soil 3 & 33 & 0.7 & 0.15 & Well graded sand \\
Soil 4 & - & - & - & Silty clay \\
Soil 5 & - & - & - & Medium plastic clay \\
\hline
\end{tabular}


plasticity or liquid limit. Wet sieve analysis showed $38.3 \%$ passing No. 200. Results indicated that the soil is a poorly graded fine sand.

\subsection{Soil type 3-a gray sand from Kaohsiung}

The third soil for tests was obtained from the land reclamation site, $\mathrm{Da}$ Lin $\mathrm{Pu}$, Kaohsiung. This site received soils from construction sites within Kaohsiung city. The soil was virtually dry with a residual moisture content of $4.57 \%$. The soil was granular with no plasticity. Therefore, this soil is a well-graded sand.

\subsection{Soil type 4-a yellow clayey silt from Hsinchu}

The fourth soil was taken from a depth of around $8 \mathrm{~m}$ in a construction site in Hsinchu. The in-situ moisture content was $12.5 \%$. The wet sieve analysis showed that $48 \%$ of the soil passed through No. 200 sieve. The soil had a liquid limit of $26 \%$ and a plastic limit of $19 \%$. The clay content of the soil is around $6 \%$. This soil is classified as low plastic silty clay.

\subsection{Soil type 5-red lin-kao clay from Taoyuan}

The fifth soil for tests was obtained from a construction site near the exit to the CKS International Airport from Highway No. 1. The soil had been excavated and stockpiled for several months. The soil was almost dry when the samples were taken for testing. The in-situ water content was $8.6 \%$. The wet sieve analysis showed $84 \%$ finer than No. 200. The soil had a liquid limit of $43 \%$ and a plastic limit of $26 \%$. The soil had a clay content of $16 \%$. This soil is classified as medium plastic clay.

\section{Re-use as construction materials}

(1) Construction soil as sub-base material. The compaction test for each soil sample was performed according to ASTM testing procedure D-698. The compaction curves of 5 soils are shown in Fig. 1. The optimum moisture content and the maximum dry density of the compacted soils are tabulated in Table 2.

The test results show that soils except soil No. 5 have very high maximum dry densities and can be used as sub-grade construction soil for demanding projects such as the Second North-South freeway of Taiwan.

(2) Construction material in construction blocks. A control construction block mixes made of clean sand was designed as specified in ASTM C 109. The river sand used in this experiment had a $c_{\mathrm{u}}$ of $3, c_{\mathrm{c}}$ of 0.8 and $D_{10}$ of $0.3 \mathrm{~mm}$. This mixture has 482 $\mathrm{kg} / \mathrm{m}^{3}$ of portland cement, a sand/cement ratio of 2.75 and a water/cement ratio of 0.48. Five construction soils were used as sand replacement to produce construction blocks. For each soil type two mixtures were obtained by varying the sand replacement ratio (50, and $100 \%)$. The amount of mixing water in the soil concrete was adjusted to ensure proper casting and curing of the composite. The water/cement ratios and the 


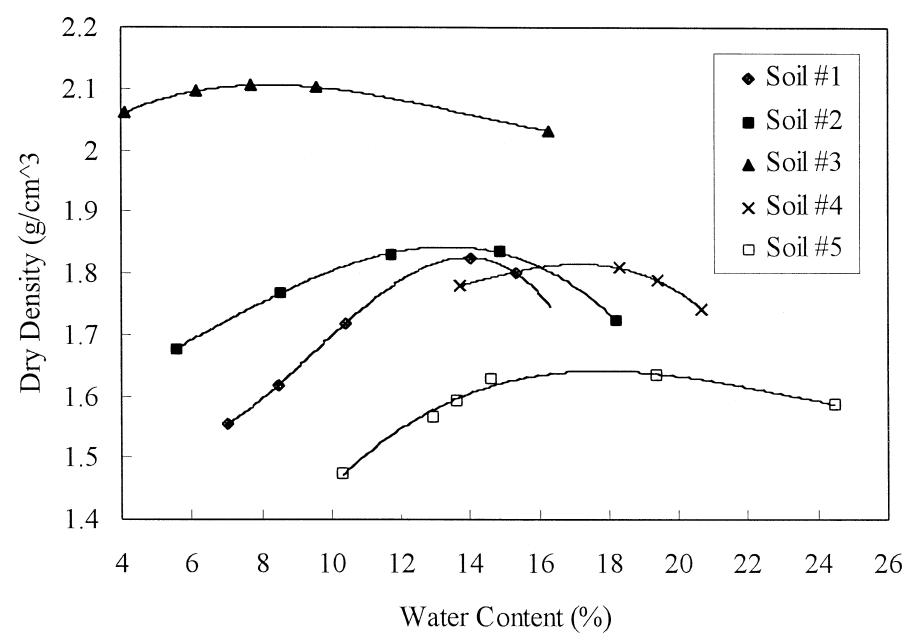

Fig. 1. Compaction curves of construction soils.

densities of each mix are listed in Table 3. It was found that finer soils need higher the water cement ratio which, in turn, resulted in a reduction in density. These data are consistent with the mechanics of soil where a soil with a higher surface area needs larger amount of water to wet the soil surface. In addition, finer soils are hard to compact by tamping and thus resulting in lower densities.

The ultimate compressive strength of soil concrete was evaluated by compressive strength tests on three $76.2 \times 76.2 \times 76.2 \mathrm{~mm}$ cubes from each mixture on $24 \mathrm{~h}, 7$ days and 28 days after casting and curing. The tests were performed following ASTM-C109 procedures. The results are summarized in Table 4.

It is noteworthy that for all mixtures at 7 days more than $50 \%$ of the 28 day strength were obtained. However, the one day strength varied from $10 \%$ to $33 \%$. Therefore, it may conclude that there is a delay in pozzolanic action due to soil but it is not detrimental. The clay soil produced the weakest mix followed by silty clay and silts. All soils produced mixes that had strengths higher than $3.45 \mathrm{MPa}$. Therefore, all five soils may be used to make cement blocks. Soil No. 3 and soil No. 2 with $50 \%$ sand produced mixes of comparable strength to that expected from control (strength more than 13.8 $\mathrm{MPa}$ ). Addition of sand in the mixture significantly improved the strength. The

Table 2

Summary of compaction test results

\begin{tabular}{llc}
\hline Soil type & Maximum dry density $\left(\mathrm{g} / \mathrm{cm}^{3}\right)$ & Optimum water content $(\%)$ \\
\hline Soil 1 & 1.83 & 13.5 \\
Soil 2 & 1.84 & 13.0 \\
Soil 3 & 2.10 & 8.00 \\
Soil 4 & 1.81 & 16.5 \\
Soil 5 & 1.63 & 17.5 \\
\hline
\end{tabular}


Table 3

Density and water cement ratios of soil cement mortar

\begin{tabular}{lll}
\hline Mix & Density $\left(\mathrm{g} / \mathrm{cm}^{3}\right)$ & Water/cement $(\%)$ \\
\hline Control & 1.940 & 48.4 \\
Soil No. $1100 \%$ & 1.635 & 80.4 \\
Soil No. $150 \%$ & 1.828 & 64.4 \\
Soil No. $2100 \%$ & 1.844 & 80.4 \\
Soil No. $250 \%$ & 1.940 & 64.4 \\
Soil No. $3100 \%$ & 1.988 & 72.4 \\
Soil No. $350 \%$ & 1.988 & 56.4 \\
Soil No. $4100 \%$ & 1.908 & 88.4 \\
Soil No. $450 \%$ & 1.876 & 64.4 \\
Soil No. $5100 \%$ & 1.603 & 88.4 \\
Soil No. $550 \%$ & 1.780 & 68.4 \\
\hline
\end{tabular}

accidental testing of mix with soil No. 3 and higher water cement ratio produced a strong mix. This observation prompted the investigation of the influence of water cement ratio on the strength for concrete.

(3) Construction soil in structural concrete mixtures. A control construction block mixes made of clean sand was designed. The cement sand and coarse aggregate ratios were 1:1.5:1.5 by weight respectively. The coarse aggregate passed through US $3 / 8^{\prime \prime}$ sieve but was retained on US No. 4 sieve. The sand was passing US No. 4 sieve. This mixture had $422 \mathrm{~kg} / \mathrm{m}^{3}$ of portland cement and a water/cement ratio of 0.48 . Five construction soils were used as sand replacement to produce concrete. For each soil type two mixtures were obtained by varying the soil/sand ratio (50\% and $100 \%)$. Since cement blocks produced with clayey soil were weak, it was decided to have a mixture of all five soils in equal proportions. This soil was termed soil No. 6. The amount of

Table 4

Compressive strengths of cement cubes

\begin{tabular}{|c|c|c|c|}
\hline Mix & $24 \mathrm{~h}$ strength $(\mathrm{kPa})$ & 7 Day strength $(\mathrm{kPa})$ & 28 Day strength $(\mathrm{kPa})$ \\
\hline Control & 5611.3 & $13,047.3$ & $16,971.3$ \\
\hline Soil No. 1 100\% & 1373.4 & 6249.0 & $10,006.2$ \\
\hline Soil No. $150 \%$ & 3443.3 & $10,398.6$ & $11,379.6$ \\
\hline Soil No. 2 100\% & 1706.9 & 6504.0 & $10,202.4$ \\
\hline Soil No. $250 \%$ & 4787.3 & $12,066.3$ & $13,635.9$ \\
\hline Soil No. $3100 \%$ & 2158.2 & 8093.3 & $16,284.6$ \\
\hline Soil No. $3^{\mathrm{a}} 100 \%$ & $\mathrm{~N} / \mathrm{A}$ & $15,499.8$ & $\mathrm{~N} / \mathrm{A}$ \\
\hline Soil No. $350 \%$ & 2511.4 & $16,284.6$ & $16,578.9$ \\
\hline Soil No. 4 100\% & 2217.1 & 6592.3 & 6298.0 \\
\hline Soil No. $450 \%$ & 2119.0 & 7328.1 & $10,791.0$ \\
\hline Soil No. 5 100\% & 725.9 & 2913.6 & 4414.5 \\
\hline Soil No. $550 \%$ & 1638.3 & 5503.4 & 8819.2 \\
\hline Soil No. $6^{\mathrm{b}} 100 \%$ & $\mathrm{~N} / \mathrm{A}$ & 5169.9 & $\mathrm{~N} / \mathrm{A}$ \\
\hline
\end{tabular}

\footnotetext{
${ }^{\text {a }}$ Higher water content.

b A mixture of all five soils (20\% each).

N/A Not available.
} 
Table 5

Density and water cement ratios of soil cement mortar

\begin{tabular}{lll}
\hline Mix & Density $\left(\mathrm{g} / \mathrm{cm}^{3}\right)$ & Water $/$ cement $(\%)$ \\
\hline Control & 2.197 & 48.0 \\
Soil No. $1100 \%$ & 2.148 & 62.3 \\
Soil No. $150 \%$ & 2.164 & 55.0 \\
Soil No. $2100 \%$ & 2.180 & 55.0 \\
Soil No. $250 \%$ & 2.197 & 50.0 \\
Soil No. $3100 \%$ & 2.309 & 55.0 \\
Soil No. $350 \%$ & 2.293 & 50.0 \\
Soil No. $4100 \%$ & 2.084 & 72.5 \\
Soil No. $450 \%$ & 2.116 & 65.0 \\
Soil No. $5100 \%$ & 2.020 & 80.0 \\
Soil No. $550 \%$ & 2.116 & 65.0 \\
Soil No. $6100 \%$ & 2.180 & 60.0 \\
\hline
\end{tabular}

mixing water in the soil concrete was adjusted to ensure proper casting and curing of the composite. The water cement ratios and the densities of each mix are given in Table 5 . A mechanical vibrator was used to densify the concrete, hence much more consistent densities were obtained.

The ultimate compressive strength of soil concrete must be evaluated to determine the suitability of using construction soil in structural concrete. The tests were conducted in accordance to ASTM-C469 procedures. Compressive strength tests were conducted using two $100 \times 200 \mathrm{~mm}$ cylinders from each mixture $24 \mathrm{~h}, 7$ days and 28 days after casting. At the time the 28 day compressive strength was determined, the stress-strain relationship was also obtained for each of the specimens. The results are listed in Table 6. It is noteworthy that except for the two clayey soils all the other mixtures at 7 days had more than $50 \%$ of the 28 day strength. However, the one day strength varied from $15 \%$ to $33 \%$.

Table 6

Compressive strengths of concrete cylinders

\begin{tabular}{|c|c|c|c|c|}
\hline Mix & $24 \mathrm{~h}$ strength $(\mathrm{MPa})$ & 7 Day strength (MPa) & 28 Day strength $(\mathrm{MPa})$ & 28 Day modulus $(\mathrm{MPa})$ \\
\hline Control & 14.47 & 24.04 & 33 & 4080 \\
\hline Soil No. 1 100\% & 10.14 & 23.48 & 23.5 & 3340 \\
\hline Soil No. $150 \%$ & 12.43 & 28.68 & 28.32 & 4200 \\
\hline Soil No. 2 100\% & 14.12 & 30.08 & 24.86 & 3820 \\
\hline Soil No. $250 \%$ & 17.29 & 30.89 & 30.28 & 5060 \\
\hline Soil No. 3 100\% & 14.2 & 30.77 & 39.54 & 6400 \\
\hline Soil No. $350 \%$ & 15.23 & 23.35 & 31.94 & 4370 \\
\hline Soil No. 4 100\% & 5.56 & 7.86 & 21.2 & 3440 \\
\hline Soil No. $450 \%$ & 10 & 19.27 & 25 & 4000 \\
\hline Soil No. $5100 \%$ & 5.12 & 8.66 & 15.4 & 3000 \\
\hline Soil No. $550 \%$ & 8.16 & 16.05 & 25.85 & 4570 \\
\hline Soil No. $6100 \%$ & 6.82 & 25.5 & 29.9 & 4160 \\
\hline
\end{tabular}


Table 7

Compressive strengths of concrete cylinders

\begin{tabular}{lcll}
\hline Mix & Water $/$ cement $(\%)$ & Density $\left(\mathrm{g} / \mathrm{cm}^{3}\right)$ & 28 Day strength $(\mathrm{MPa})$ \\
\hline Control & $45 \%$ & 2.221 & 48.9 \\
Control & $48 \%$ & 2.197 & 33 \\
Control & $55 \%$ & 2.160 & 35.4 \\
Soil No. $2100 \%$ & $47.5 \%$ & 2.062 & 12.1 \\
Soil No. $2100 \%$ & $55 \%$ & 2.180 & 24.8 \\
Soil No. $2100 \%$ & $60 \%$ & 2.112 & 32.2 \\
Soil No. $2100 \%$ & $65 \%$ & 2.086 & 26.5 \\
Soil No. $3100 \%$ & $47.5 \%$ & 2.011 & 13.1 \\
Soil No. $3100 \%$ & $55 \%$ & 2.309 & 39.5 \\
Soil No. $3100 \%$ & $60 \%$ & 2.246 & 34.6 \\
Soil No. $3100 \%$ & $65 \%$ & 2.180 & 25 \\
Soil No. $5100 \%$ & $70 \%$ & 2.052 & 11.3 \\
Soil No. $5100 \%$ & $80 \%$ & 2.020 & 14.4 \\
Soil No. $5100 \%$ & $85 \%$ & 2.014 & 12.2 \\
Soil No. $5100 \%$ & $90 \%$ & 1.961 & \\
\hline
\end{tabular}

Therefore, it may conclude that there is a delay in pozzolanic action due to the soil in the mix. More than seven days was necessary for the specimens to gain substantial strength. In addition, the clayey soil produced the weakest mix followed by silty clay and silts. All soils except mix having $100 \%$ soil No. 5 produced strengths higher than 17.25 MPa. Therefore, soil No. 1, 2, 3 and 4 may be used to make concrete. Soil No. 3 produced a mix $20 \%$ stronger than that to that of the control. The addition of sand produced strengths comparable to the control mix. Even the clayey soil produced a mix with a $80 \%$ strength of the control mix. Blending of all soils may bring the mix strength close to that of the control. Elastic moduli of all soil mixes except for soil No.3 was lower than that of control. Mix with clay soil had the lowest modules. The addition of sand brought the elastic modulus values of all mixes comparable to that of the control mix.

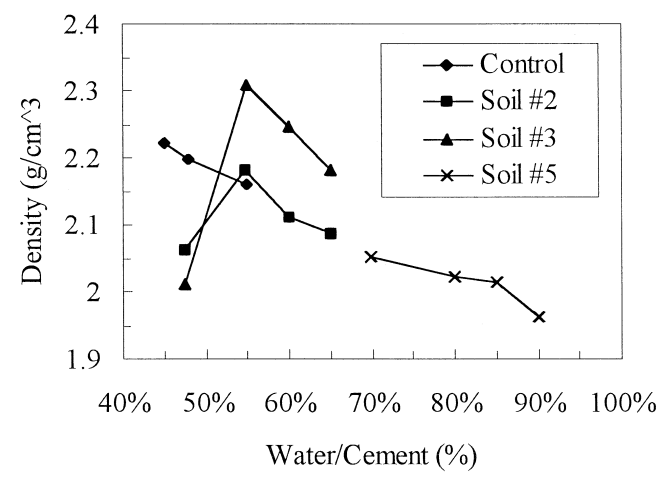

Fig. 2. Relationship between density and water content. 


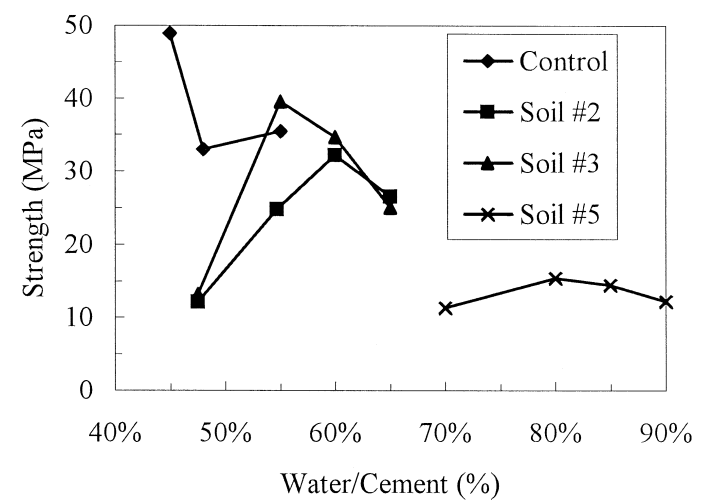

Fig. 3. Relationship between compressive strength and water content.

Since the water content of the mixture appeared to influence the strength of the mix, it was decided to evaluate the contribution of water content to the compressive strength. Test results are reported in Table 7 and plotted in Figs. 2 and 3. Fig. 2 shows that the variation of density with water/cement ratio behaves very similarly to that of compacted soils. There appears to be maximum density corresponding to optimum water/cement ratio. In addition, concrete specimens with the above optimum water/cement ratio have the highest strengths (Fig. 3).

The wet-dry durability test was conducted in accordance to ASTM D-559. The concrete was subjected to 12 wet-dry cycles after it had been cast and cured for 28 days. Each cycle was $48 \mathrm{~h}$ with $6 \mathrm{~h}$ submerged in a water bath followed by $42 \mathrm{~h}$ in an oven at $71^{\circ} \mathrm{C}$. After each cycle the specimen was brushed 25 times around with a wire brush. The percentage loss in weight due to brushing is recorded. The accumulated percentage loss and the compressive strength after 12 cycles are reported in Table 8 . The durability test shows all samples except for concrete made with $100 \%$ soil No. 2 and $100 \%$ soil No. 3 experienced much higher weight loss than that for control. However,

Table 8

Wet and dry durability test results for concrete cylinders

\begin{tabular}{lll}
\hline Mix & Percentage loss & Strength (MPa) \\
\hline Control & 2.064 & 54.06 \\
Soil No. $1100 \%$ & 5.811 & 32.16 \\
Soil No. $150 \%$ & 5.082 & 47.4 \\
Soil No. $2100 \%$ & 0.052 & 39.33 \\
Soil No. $250 \%$ & 6.548 & 49.22 \\
Soil No. $3100 \%$ & 1.983 & 34.73 \\
Soil No. $350 \%$ & 3.313 & 34.94 \\
Soil No. $4100 \%$ & 4.788 & 24.64 \\
Soil No. $450 \%$ & 4.069 & 29.87 \\
Soil No. $5100 \%$ & 6.118 & 20.35 \\
Soil No. $550 \%$ & 7.628 & 27.87 \\
Soil No. $6100 \%$ & 2.978 & 35.3 \\
\hline
\end{tabular}


Table 9

Grain size distribution of aggregates

\begin{tabular}{|c|c|c|c|c|}
\hline \multirow[t]{2}{*}{ Size or US sieve } & \multicolumn{4}{|l|}{ Percent retained } \\
\hline & $3 / 4^{\prime \prime}$ aggregates & $1 / 2^{\prime \prime}$ aggregates & $3 / 8^{\prime \prime}$ aggregates & $\overline{\text { River/sand }}$ \\
\hline $3 / 4^{\prime \prime}$ & 1.0 & & & \\
\hline $3 / 8^{\prime \prime}$ & 90.0 & 95.0 & 12.0 & \\
\hline No. 4 & 9.0 & 5.0 & 71.0 & 1.0 \\
\hline No. 10 & & & 17.0 & 33.0 \\
\hline No. 40 & & & 0.0 & 42.0 \\
\hline No. 100 & & & 0.0 & 20.0 \\
\hline No. 200 & & & 0.0 & 2.0 \\
\hline Pan & & & 0.0 & 0.0 \\
\hline
\end{tabular}

the compressive strength of all the samples except concrete made with $100 \%$ soil No. 3 gained significantly. This indicates that all specimens continue with the pozzolanic action beyond 28 days and there seems to be no detrimental effects due to wetting and drying.

(4) Construction soils in hot mix asphalt concrete production. All five soil samples were tested for inclusion in hot mix asphalt concrete. The aggregate samples and asphalt cement were obtained from the In-Tai, Hsinchu. Procedure for sampling is given in ASTM D75. The sieve analysis data for the aggregates and the construction soils are given in Tables 9 and 10, respectively.

Asphalt concrete specification requires that particle sizes be within a certain range of sizes and each particle size to be present in a certain proportion. The distribution of particle sizes within the aggregate is called the gradation curve of the aggregate ([6]). Paving mixtures are classified according to the maximum size or nominal maximum size of aggregate. The construction code along side of the names of the mixes describes the maximum aggregate size and the type of asphalt mix. The maximum size particle for each category in Taiwan is as follows: I-1 is $1.5^{\prime \prime}$; I-2 is $1^{\prime \prime} 0$; I-3 is $3 / 4^{\prime \prime}$; I-4 is $1 / 2^{\prime \prime}$; and I-5 is $3 / 8^{\prime \prime}$.

The strength of the HMA concrete depends on the aggregate blend. Tests were performed on all the asphalt concrete with soils for an I-3 mix which is intended for the bottom layer of the surface course. The I-3 mix is an extensively used medium grade asphalt concrete designed for heavy traffic conditions. A control was designed and tested

Table 10

Grain size distribution of construction soil

\begin{tabular}{|c|c|c|c|c|c|}
\hline \multirow[t]{2}{*}{ Size or US sieve } & \multicolumn{5}{|c|}{ Percent retained } \\
\hline & Soil No. 1 & Soil No. 2 & Soil No. 3 & Soil No. 4 & Soil No. 5 \\
\hline No. 4 & & & 20.0 & & \\
\hline No. 8 & & & 17.0 & & \\
\hline No. 30 & 10.0 & 3.0 & 40.0 & 10.0 & \\
\hline No. 200 & 85.0 & 77.0 & 17.0 & 42.0 & 16.0 \\
\hline
\end{tabular}


Table 11

Optimum aggregate/soil percentages for I-3 mix

\begin{tabular}{lllllll}
\hline Aggregate type & Control & Soil No. 1 & Soil No. 2 & Soil No. 3 & Soil No. 4 & Soil No. 5 \\
\hline $3 / 4^{\prime \prime}$ aggregate & 10.0 & 10.0 & 10.0 & 10.0 & 10.0 & 10.0 \\
$1 / 2^{\prime \prime}$ aggregate & 25.0 & 25.0 & 25.0 & 20.0 & 25.0 & 25.0 \\
$3 / 8^{\prime \prime}$ aggregate & 25.0 & 25.0 & 25.0 & 20.0 & 25.0 & 25.0 \\
River sand & 40.0 & 30.0 & 30.0 & 0.0 & 35.0 & 35.0 \\
Soil & 0.0 & 10.0 & 10.0 & 50.0 & 5.0 & 5.0 \\
\hline
\end{tabular}

for comparisons. The control consisted of $3 / 4^{\prime \prime}$ size, $1 / 2^{\prime \prime}$ size and $3 / 8^{\prime \prime}$ size aggregates, and sand.

The optimum percentages that may be used in I-3 mix for each soil type are shown in Table 11 . It can be clearly seen that as much as $50 \%$ soil No. 3 may be included instead of the aggregates in the HMA. For soils No. 1 and No. 2 which are silty soils, the maximum is only $10 \%$. The above procedure is required for hot as well as cold mix asphalt concrete. Once the maximum amount of soil that may be added to HMA is determined, the suitability of such an addition should be evaluated.

The Marshall test method (ASTM D-1559-82) was used to determine the suitability of hot mix asphalt mixes for paving. The density, Marshall strength, air voids, VMA, and flow with asphalt content of 4,5 , and $6 \%$ were determined for the control and the soils. Asphalt content values corresponding to the minimum density and stability, and the maximum VMA were used to obtain the optimum asphalt content (average of three values) to be used in designs. The optimum asphalt concentrations for the six soils and the construction specification for high traffic volume I-3 mix are shown in Table 12. If an asphalt concrete meets all the applicable specifications and if it is a workable mix, it will be acceptable as a paving material.

It can be concluded from the Table 12 that all the mixes except those with soil No. 2 and soil No. 4 satisfy the construction specifications. If the two mixes that failed were to tested at asphalt content higher than $6 \%$ those two will also satisfy the specifications. Hence, it can be concluded that the above mixes with five different soils can be used to produce hot mix asphalt concrete.

Table 12

Optimum properties of HMA made with soils for I-3 mix

\begin{tabular}{llrrrrrr}
\hline $\begin{array}{l}\text { Asphalt concrete } \\
\text { property }\end{array}$ & $\begin{array}{l}\text { Allowable } \\
\text { for NJ I-3 mix }\end{array}$ & Control & Soil No. 1 & Soil No. 2 & Soil No. 3 & Soil No. 4 & Soil No. 5 \\
\hline Strength (N) & $>6672$ & 12400 & 16600 & 13500 & 10400 & 12700 & 11800 \\
Flow (0.25 mm) & $6.0-16.0$ & 10.0 & 10.0 & 7.0 & 6.0 & 6.0 & 6.0 \\
Air voids (\%) & $3.0-5.0$ & 5.0 & 5.0 & 6.5 & 4.5 & 6.5 & 5.0 \\
VMA (\%) & $>13.0$ & 23.0 & 19.0 & 20.0 & 17.0 & 20.0 & 23.5 \\
Density $\left(\mathrm{kN} / \mathrm{m}^{3}\right)$ & $\mathrm{N} / \mathrm{A}$ & 20.9 & 22.0 & 21.8 & 23.5 & 21.8 & 20.5 \\
Optimum asphalt & N/A & 5.0 & 6.0 & 6.0 & 5.0 & 6.0 & 5.0 \\
content $(\%)$ & & & & & & & \\
\hline
\end{tabular}

N/A: Not available. 


\section{Summary and conclusions}

The purpose of the research was to study the performance of construction materials made with abandoned soils. Four types of construction materials, namely sub-base soil, cement block, structural concrete, and asphalt concrete were studied. Five soils representative of the soil types predominant in major cities of Taiwan were selected in this study. The soils tested in this study included sandy, silty, and clayey soils.

The compaction test results demonstrated that all five soils are suitable as sub-grade construction soils. Soil No. 3 with very high maximum dry density can be used as sub-base material. All soils except soil No. 5 are strongly recommended as sub-grade construction soils for all highway construction projects.

The compression tests for cement mortar made with five soils showed that for all mixtures had more than $50 \%$ of the 28 day strength after seven days. All soils produced mixes that had strengths higher than $3.45 \mathrm{MPa}$. Therefore, all five soils may be used to make cement blocks. Addition of sand significantly improved the strength.

The major part of this study was devoted to the use of abandoned soil in concrete. The compressive strength test results show that except for the two clayey soils all the other mixtures at seven days had more than $50 \%$ of the 28 day strength. All soils except mix having $100 \%$ soil No. 5 produced strengths higher than $17.25 \mathrm{MPa}$. Therefore, soil \# 1, 2, 3 and 4 may be used to make concrete. The addition of sand brought the elastic modulus values of all mixes comparable to that of the control mix.

The second series of tests investigating the influence of water content showed that the variation of density with water/cement ratio behaves very similarly to that of compacted soils. There appears to be maximum density corresponding to optimum water/cement ratio and concrete samples produced at this optimum water/cement ratio have the highest strengths. The wet/dry durability test showed that the pozzolanic action of all concrete samples made with soils continued beyond 28 days and there seems to be no detrimental effects due to wetting and drying.

A comprehensive mix design was performed for each soil type to test the use of abandoned soils in hot mix asphalt concrete. All five soils can be used in the production of hot mix asphalt concrete. However, soil No. 3 was the best candidate with $50 \%$ by weight in the mixture. All the mixes except those with soil No. 2 and soil No. 4 satisfied the construction specifications. The two mixes that failed, if tested at an asphalt content higher than $6 \%$, then those two will also satisfy the specifications.

The abandoned soils can and should be used in construction. Sandy construction soil should never be wasted, as it was much superior to the virgin construction materials that were used in all types of construction applications. Clayey soils should be used with caution in all construction applications. If clayey soil is blended with other soils it is a good material in all construction applications. In the future, the material recycling center receiving the abandoned soil should try to mix all the soils and used in construction. Using the soil for sub-grade construction would be the most obvious way to consume large volume of the abandoned soils. When the abandoned soils are to be used to produce other construction materials, the best cost effective application without detrimental effect would be to use them in cement block production. If soils are used in making concrete, they should be used only as mass concrete and should not be used in 
reinforced concrete as this study did not investigate the effect of soil on reinforcement. Only sandy soils should be used in making asphalt concrete as up to $50 \%$ by weight of the mixture although other types of soils can also be used after cautious design.

In addition to the experiments, a limited survey performed to determine the receptiveness of the construction industry also show promising results. It strongly suggests the entrepreneurs will adopt the proposed ideas based on the economical benefits. Judging from the global environment of construction industry in Taiwan, it is believed that the reuse of abandoned soils will begin in the very near future. It is very important that regulators control the process so that entrepreneurs in the construction industry do not exploit the situation to make excessive profits. This situation can be controlled if a set of design standards and a method to enforce on the design standards can be developed so that final products meet or exceed the existing construction material specifications.

\section{Acknowledgements}

This research and Dr. Jay N. Meegoda's visiting in National Chaio Tung University are funded by National Science Council of Taiwan, Republic of China through Grant NSC84-2611-E009-008. The authors also thank Mr. Jin-Fu Huang, Mr. Jia-Wen Tseng and Ms. Su-Hwa Cheng for their help in conducting the laboratory tests.

\section{References}

[1] P.C. Kreijger (Ed.), Adhesion problems in recycling of concrete, Plenum (1980), 419 pp.

[2] R.J. Collins, Assimilation of waste and by-products into the highway system: status report and regulatory influences, 2nd Inter-agency Symposium on Soil Stabilization, New Orleans, LA, section 7, November 1992, pp. 3-11.

[3] L. Flynn, Recycling: will roads become linear landfills? Roads and Bridges, October, 1992, pp. 65-70.

[4] R. Czarnecki, Making use of contaminated soils, Civil Eng., ASCE, December 1988, pp. $72-74$.

[5] R. Czarnecki, Hot Mix Asphalt Technology and Cleaning of Contaminated Soils, in: P. Kostecki, E.J. Calabrese (Eds.), Petroleum Contaminated Soils, vol. 2, Lewis Publishers (1989).

[6] Asphalt Institute, The asphalt handbook, Asphalt Institute, MS-4, 1989. 